\title{
A identidade social estigmatizada de pobre: uma constituição opressora ${ }^{\star}$
}

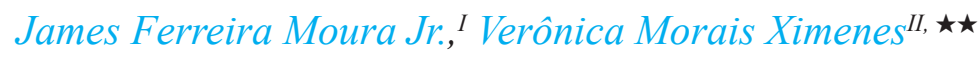 \\ ${ }^{I}$ Universidade da Integração Internacional da Lusofonia Afro-Brasileira, Redenção, CE, Brasil

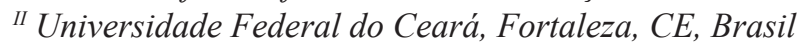

\begin{abstract}
Resumo
A pobreza é abordada como prática de opressão, desenvolvendo constituições identitárias depreciativas do individuo. Este artigo analisa os papéis sociais da identidade social estigmatizada de pobre. A pesquisa foi realizada com 4 pessoas em situação de rua vinculadas ao Abrigo Provisório da Prefeitura Municipal de Fortaleza. Foram utilizados como instrumentos a observação participante e a entrevista narrativa, tendo a análise temática narrativa como procedimento de análise. Foram identificados os papéis sociais de conformado, de crente em Deus como responsável por tudo, de mártir, de causa de mazelas sociais e de culpado pela sua situação. Concebe-se que esses papéis sociais permeiam as relações sociais e a identidade, enfraquecendo e depreciando as potencialidades do indivíduo em situação de pobreza. É importante para os profissionais de Psicologia o entendimento desses papéis para elaboração de possiveis intervenções com foco no enfrentamento da situação de pobreza.
\end{abstract}

Palavras-chave: identidade; psicologia; pobreza; situação de rua.

\section{Stigmatized social identity of poor: an oppressing constitution}

\begin{abstract}
Poverty is addressed as oppression practice, developing depreciative identitary constitutions of the individual. This article examines the social roles of stigmatized social identity of poor. The research was performed with 4 people in street situation linked to Provisional Shelter of the Municipal Prefecture of Fortaleza. The used instruments were participant observation and narrative interview, having thematic analysis as procedure. It was identified the social roles of conformed, of believer in God as responsible for everything, of martyr, of cause of social malaise and of guilty for their situation. It is conceived that these social roles permeate social relations and identity, weakening and depreciating the potentialities of the poor individual. It is important for practitioners of Psychology to the understanding of these roles to draw up possible interventions focused on confronting of this situation of poverty.
\end{abstract}

Keywords: identity. psychology. poverty. street situation.

\section{Introdução}

A pessoa em situação de pobreza é constantemente vítima de um processo de discriminação, estando inserida em um processo reconhecimento depreciativo histórico (SIQUEIRA, 2006; SPRANDEL, 2004). A pobreza, como uma prática de opressão, repercute geralmente de forma danosa na vida dos indivíduos situados nessa condição, desde uma constituição identitária baseada em atitudes de inferioridade (MOANE, 2003), de passividade (MARTÍN BARÓ, 1998) e de violência (GÓIS, 2005) até danos nas condições físicas de saúde (RODRÍGUEZ, 2006) e no bem estar pessoal (HOWELL, R.; HOWELL, C., 2008; PRILLELTENSKY, 2008). Essas repercussões podem ser entendidas como parte do processo de desenvolvimento da identidade social de pobre ${ }^{1}$ que tem uma perspectiva histórica estigmatizante.

É necessário conceber a pobreza em sua complexidade, pois ela é constituída também de fatores sociais, políticos e simbólicos, funcionando como uma estratégia de manutenção do status quo. Há a uma série de práticas,

\footnotetext{
^ Presta-se agradecimentos a Coordenação de Aperfeiçoamento de Pessoal de Nível Superior (Capes) pelo financiamento desta investigação.

$\star \star$ Endereço para correspondência: Universidade Federal do Ceará, Centro de Humanidades, Departamento de Psicologia. Av. da Universidade, 2762 - Benfica. CEP: 60020180 - Fortaleza, CE - Brasil.E-mail: james.mourajr@unilab. edu.br, vemorais@yahoo.com.br

É importante salientar que é utilizado o termo "pobre", porque ele representa o viés opressor e cerceador contido na estruturação dessa identidade social estigmatizada que será analisada nesta produção. Evidencia-se que a pobreza e a própria identidade devem ser concebidas como estados mutáveis, devendo criticamente ser utilizado de forma respeitosa e compreensiva o termo pessoa em situação de pobreza. Assim, este artigo utilizará os dois termos: pessoa em situação de pobreza quando referente aos indivíduos inseridos nesse contexto; e identidade social de pobre quando referente a essa perspectiva estigmatizada.
}

valores e crenças que delimitam o modo de viver das pessoas em situação de pobreza, desenvolvendo essa forma específica de identidade que é "negada, sofrida, desamparada, frágil, e também violenta" (GÓIS, 2008, p. 60). Dessa maneira, uma das formas de enfrentar essa situação é explicitar os percursos de desenvolvimento dessa identidade social estigmatizada de pobre, evidenciando suas tramas opressoras.

Segundo Oliveira e Amorim (2012), construir estratégias inovadores de atuação junto ao público em situação de pobreza faz parte da atuação dos profissionais de Psicologia que atuam nas políticas públicas de Assistência Social e Saúde. No entanto, para isso ocorrer é necessário um maior conhecimento sobre os mecanismos opressores que permeiam a identidade social de pobre. Assim, este trabalho tem como objetivo analisar os papéis sociais dessa identidade social estigmatizada de pobre a partir das histórias de vida de pessoas em situação de rua da cidade de Fortaleza.

\section{O processo de construção histórica da identidade social estigmatizada de pobre}

A identidade social estigmatizada de pobre é lesiva, porque as sociedades estruturam essas identidades em aspectos pressupostos, ou seja, em formas cristalizadas de reconhecimento do indivíduo. Ela impede o processo de transformação da identidade metamorfose, enfraquecendo as possibilidades de mudança tanto do indivíduo reconhecido por esse prisma identitário estigmatizado, como das políticas de identidade presentes na sociedade. Ciam- 
pa (2002) fala que a política de identidade de um determinado grupo ou coletividade refere-se a uma identidade social que é pressuposta a partir de orientações e critérios que constituem estruturas de reconhecimento específicas.

O que parece de forma inicial é o fato de que determinadas políticas de identidade configuram determinadas identidades coletivas [...]. Assim, tais políticas identitárias acabam por expressar um tipo de discurso a favor de uma autodeterminação excludente, o que significa que dentro de tais políticas o indivíduo acaba por se colocar diante do outro de forma estigmatizada. (LIMA, 2010, p. 170)

Essa política de identidade, então, pode ser constituída por estigmas. A identidade social estigmatizada, segundo Goffman (2008[1963]), carrega um estigma que repercute no reconhecimento da pessoa em somente uma via de compreensão opressora. Por conta disso, Zavaleta Reyles (2007) afirma que a pessoa em situação de pobreza pode sentir-se humilhada e envergonhada somente por conta de sua condição, enfraquecendo, assim, sua capacidade de enfrentamento da realidade. Dessa maneira, há uma identidade social específica e estigmatizada de pobre que é formada a partir de papéis sociais. Esses papéis, segundo Lane (1984), carregam normas de conduta relativamente estáveis criadas a partir dos modos de produção de uma sociedade. Eles reproduzem os processos de dominação existentes, construindo-se de forma naturalizada e ideológica como maneira de manutenção de uma ordem social opressora e desigual.

Os papéis sociais constituintes da identidade social, para Ciampa (1977), advém de funções sociais existentes na realidade construídas historicamente a partir da padronização das atividades realizadas pelos seres humanos, sendo, segundo Lane (1981), um mecanismo de controle, de manipulação e de reprodução de uma identidade social pressuposta. Esses papéis somente existem porque são materializados pelas pessoas e pelos grupos. Dessa maneira, a "identidade é ao mesmo tempo pessoal no sentido de ser 'localizada' numa pessoa e social na medida em que os processos de sua formação são sociais" (DESCHAMPS; MOLINER, 2009, p. 22).

A identidade é constituída desses papéis sociais, sendo baseada no materialismo histórico dialético, pois o ser humano é concebido como matéria. Essa matéria também se refere à realidade social, ao grupo familiar e às instituições que particularizam o universal. Segundo Ciampa (1987), cada ser humano, na sua materialidade, é encarnado pelas relações sociais que são históricas. No entanto, o ser humano não é constituído por essa historicidade de forma passiva, pois a propriedade da matéria é a transformação. Assim, ontologicamente, o ser humano é abordado como devir, o ser que é mudança, formando, dessa maneira, a identidade metamorfose.

Apesar da identidade metamorfose ser sinônimo de mudança e inovação, Góis (2008) e Ciampa (1984) concebem que a classe social em que a pessoa está situada repercute em uma estruturação específica na identidade. Isso ocorre, porque a realidade social, a partir de seu conhecimento compartilhado, interfere na constituição identitária, cristalizando relações de opressão e constituindo uma forte violência simbólica aos indivíduos oprimidos a partir da reprodução de papéis sociais específicos. Essa violência simbólica, segundo Mattos e Ferreira (2004), geralmente, é a motivadora para a existência da violência física impetrada as pessoas portadoras de um determinado estigma.

A pessoa em situação de pobreza pode ser abordada como possuidora de uma identidade de oprimido e de explorado que está baseada na sobrevivência, na violência e no medo fruto de uma ordem social opressora.

A identidade de oprimido e de explorado é um modo de sobrevivência social, biológica, psicológica e espiritual, construída alienada e inconscientemente pelo povo pobre para reduzir sua angústia e sofrimento diante da miséria e da violência, para não ser eliminada socialmente, nem psíquica e fisicamente. É um tipo de identidade que não integra socialmente os indivíduos e os mantém separados, individualizados, dentro de sua coletividade. É uma tentativa de resistir ao caminho de exploração, doença e morte imposto pela classe dirigente, cujo final é representado pela penitenciária, hospital, manicômio ou cemitério (GÓIS, 2008, p. 61-62).

Para entender o processo de constituição opressor da identidade social estigmatizada de pobre, foi utilizada a compreensão da situação de rua como uma vivência de pobreza. Segundo Pereira (2007), é consenso entre teóricos acadêmicos, políticos, cidadãos comuns e instituições sociais que as pessoas em situação de rua representam a faceta mais evidente e perversa da pobreza. Segundo Mattos e Ferreira (2005), a estrutura social da pobreza é uma das causas da situação de rua. O Ministério do Desenvolvimento Social e Combate a Fome (MDS) identifica que

[...] as pessoas em situação de rua constituem uma parcela da população brasileira nos limites inferiores de pobreza e de vulnerabilidade. É uma população que, além de extremamente pobre, é escassamente escolarizada e se compõe predominantemente de negros, que, embora estando predominantemente em idade economicamente ativa, não conseguem inserção no mercado formal de trabalho (BRASIL, 2009, p. 101).

A pobreza não é abordada neste estudo somente a partir do cunho da insuficiência econômica, mas está impregnada de fatores de privação e de opressão simbólicos, sociais, psicológicos, estruturais e materiais (MOURA JR. et al., 2014), emergindo da concepção de pobreza como um estado de privação de liberdade em diversos âmbitos de acordo com Sen (2000). Essa pobreza é construída historicamente, fazendo parte da realidade brasileira desde o período colonial até o dias atuais. Há uma série de explicações posicionando as pessoas em situação de pobreza como os motivos para o atraso econômico brasileiro (MOURA JR.; XIMENES; SARRIERA, 2014). Ribeiro (2005, p. 17-18) sustenta que "a sociedade e a cultura brasileira são conformadas como variantes da versão lusitana da tradição civilizatória européia ocidental, diferenciadas por coloridos herdados dos índios americanos e dos negros africanos". A pobreza, segundo Sprandel (2004), pode ser percebida como consequência da escravidão e da exploração da colônia Brasil pela 
metrópole Portugal, do sistema monocultor baseado no latifúndio e da falta de políticas de inclusão dos escravos libertos no mercado de trabalho.

Para Ribeiro (2005), esse processo de colonização foi extremamente cruel, opressor e desumano. Assim, o povo brasileiro, além de possuir uma formação singular, é constituído também do legado do reconhecimento dessa identidade social estigmatizada de pobre advindo da civilização européia de acordo com Sprandel (2004), porque as raízes culturais da América Latina têm uma origem híbrida devido à colonização de suas terras e de seus povos nativos pelas culturas além-mar.

A pobreza, portanto, não se restringe somente ao modelo capitalista. Sua existência está situada desde antes do surgimento do sistema econômico vinculado ao capital (MENDONÇA, 2006; SIQUEIRA, 2006). Obviamente, apesar de não ser exclusiva do capitalismo, depois do surgimento dele é observada a expansão da pobreza principalmente com as transformações econômicas, com o neoliberalismo, a reestruturação produtiva e a centralidade do mercado financeiro. No entanto, em relação à Antiguidade, segundo Lacerda (2009), havia explicações pautadas em assunções divinas para a existência de pobres e de ricos, restando apenas o conformismo para as pessoas imersas em situação de pobreza. Dessa maneira, uma das primeiras características que constitui a identidade social de pobre é o papel social de conformado ou resignado frente à sua posição na sociedade.

Também para Ribeiro (2005), a Igreja Católica foi figura central nesse processo de domesticação conformista da pessoa em situação de pobreza, sendo uma das forças basais para a expansão portuguesa nos territórios tupiniquins, para a "homogeneização" da língua portuguesa e para a efetivação do catolicismo como principal religião do Brasil. Assim, a identidade social de pobre também pode estar vinculada ao papel social de crente em Deus como responsável por tudo que sustenta igualmente o papel social de conformado.

Na Idade Média, a pobreza já era abordada como ausência de condições materiais relacionadas a terras e a riquezas. Segundo Siqueira (2006) e Piva (2006), a pobreza tinha um lugar central na constituição societária das sociedades pré-feudais e feudais, pois estava vinculada a um ideal de sacrifício a serviço da manutenção e da justificativa da ordem social vigente. As pessoas em situação de pobreza eram vistos como desafortunados e como representação humana de Jesus Cristo, sendo geralmente posicionados com fins de caridade. Assim, à identidade social de pobre como conformado e de crente em Deus, como responsável por tudo, é somado o papel social de mártir como atitude de sacrifício em prol de um bem maior oferecido por Deus. O sofrimento causado pela pobreza é valorizado, de acordo com Piva (2006), como representação de um dos caminhos mais próximos para se chegar ao Reino dos Céus.

No desenvolvimento histórico do Brasil e da América Latina, a religião foi uma das ferramentas de manutenção da desigualdade social e da pobreza, repercutindo no fa- talismo como consequência psicológica dessa realidade opressora. Martín Baró (1998) identifica que o fatalismo é uma atitude central na constituição da população latino americana, correspondendo à predeterminação da existência, isto é, a ausência de possibilidades de mudança. Há uma estrutura macrossocial que impede a transformação da identidade, situando o ser humano em uma posição de impotência e de submissão onde o conformismo e a obediência são atos manifestados através de uma crença religiosa. Sob nossa ótica, a própria estrutura societária e a religião ${ }^{2}$ funcionam como ferramentas ideológicas de reprodução do status quo e, assim, das atitudes fatalistas. Dessa forma, o fatalismo é originado a partir da realidade social, como também, mantido por meio da estrutura social e da configuração identitária do ser humano, sendo constituído pelos papéis sociais de conformado, de crente em Deus como responsável por tudo e de mártir.

Como maneira de manutenção dessas atitudes de submissão e de conformismo na população oprimida, segundo Goes (2009), a sociedade está estruturada de uma forma em que há a reprodução de ideologias, de relacionamentos, de instituições e de atitudes que estão a serviço da permanência dessa realidade de opressão. Esse movimento de manutenção do status quo efetiva a reprodução desses papéis sociais constituintes da identidade social estigmatizada de pobre. Ibañez (2000) aponta que a ideologia é o instrumento que mantém essa dialética de dominação e opressão com a capacidade de manter os indivíduos enfraquecidos para romper essa estrutura dominante e opressora. É constituído um forte caráter ideológico na estruturação da identidade. Segundo Góis (2008, p. 53), a ideologia de submissão e resignação abarca essas relações de dominação que, segundo ele, trata-se de: “'[...] uma lógica de dominação ou sistema de ideias [...] Nessa ideologia, a população em situação de pobreza é vista como subalterna, serviçal, periférica, problemática, mão de obra barata e incapaz de protagonizar sua vida".

Com isso, a sociedade é concebida como autorregulada naturalmente indicando que as pessoas que necessitam de ajuda para sobreviver encontrariam no sistema capitalista os meios para solução dos seus problemas, a partir da mínima intervenção estatal (MENDONÇA, 2006). Dessa maneira, a pobreza é concebida como responsabilidade individual. Com isso, à identidade social de pobre é acrescentada o papel social de culpado pela sua situação. Segundo Mattos e Ferreira (2004, p. 49), esse processo de culpabilização se refere a

[...] uma legitimação ideológica que suporta a criação e reprodução das relações de exploração e dominação no capitalismo. Frente à (pseudo) igualdade e à competitividade inerente ao ideal liberal, qualquer problemática que envolva a inserção do indivíduo no sistema produtivo é alvo de um reducionismo que o descontextualiza da sociedade e transfere-lhe a culpa e responsabilidade por sua condição.

${ }^{2}$ Não se pode generalizar esta informação, porque Ribeiro (2005) aborda que algumas missões jesuíticas tiveram objetivos de construção de uma nova ordem social próxima dos moldes comunistas, mas foram destruídas pela Coroa portuguesa que não compartilhava com essas ideias. Também é abordada como exceção a Teologia da Libertação que, segundo Martín Baró (1998), atuou em prol das pessoas em situação de pobreza.

Fractal, Rev. Psicol., v. 28 - n. 1, p. 76-83, 2016 
A partir do século XII até o século XIV, a população em situação de pobreza teve um crescimento exponencial devido à existência de grandes epidemias, de miséria generalizada e de conflitos sociais. Essas pessoas eram consideradas mão de obra ou mercado de reserva. No entanto, como não havia trabalho para o contingente populacional imerso na pobreza, essas pessoas viviam em condições pauperizadas, sendo vistas como desocupadas, "vagabundas" e problemáticas (PIVA, 2006). As pessoas em situação de pobreza, com isso, passaram a serem vistas como causadoras de mazelas sociais e preguiçosas, constituindo o papel social de vagabundo e de causa das mazelas sociais, sendo reconhecido, segundo Mattos e Ferreira (2004), como improdutivo, inútil e relaxado.

Em 1388 na Inglaterra, segundo Lacerda (2009), foi criada uma das primeiras políticas sociais implantadas no mundo, chamada de Lei dos Pobres com um caráter mais punitivo do que protetivo. Era uma lei que tinha uma perspectiva higienista, pois as pessoas em situação de pobreza eram reconhecidas como sujas e doentes, não podendo aproximar-se da elite rica. A identidade social de pobre foi ainda mais associada ao papel social de causa das mazelas sociais, sendo reconhecidos como deturpadores da sociedade estruturada nos moldes elitistas. Reconhecer perversamente a identidade desses indivíduos como sujos e doentes faz parte de uma política de identidade regulatória. Segundo Mattos e Ferreira (2004), a necessidade de esconder e de limpar caracteriza uma prática de higienização em que não há aceitação do diferente. Tavares (2011, p. 126) afirma que a pessoa em situação de pobreza é concebida como um "perigo social que deve ser erradicado".

Assim, a pobreza é concebida a partir das relações históricas de reconhecimento perverso dos papéis sociais de conformado, de crente em Deus como responsável por tudo, de mártir, de vagabundo, de causa de mazelas sociais e de culpado pela sua situação, desenvolvendo a identidade social estigmatizada de pobre. Com isso, concebe-se a necessidade de analisar de forma mais atenta esse processo de constituição identitária, tensionando a esses mecanismos sociais e marginalizantes desses papéis sociais relacionados ao indivíduo em situação de pobreza.

\section{Método}

Essa pesquisa tem uma perspectiva qualitativa que, segundo Alves-Mazzotti e Gewandsznajder (1998), almeja compreender de forma mais ampla o fenômeno de estudo a partir da crítica ao empirismo lógico, pois não há observação pura. Assim, quando é realizada a pesquisa, o pesquisador está situado em uma postura ética de construção de conhecimento a favor e junto das pessoas em situação de opressão, utilizando teorias e ferramentas metodológicas que os respeitem e os valorizem.

Segundo Denzin e Lincoln (2006), o pesquisador pode utilizar diversas estratégias, métodos ou materiais empíricos em sua produção, reunindo técnicas existentes ou inventadas. Assim, foi utilizada a técnica da observação proveniente do método etnográfico. Essa técnica, segundo Angrosino (2009), tem o objetivo de propiciar a

Fractal, Rev. Psicol., v. 28 - n. 1, p. 76-83, 2016 inserção efetiva do pesquisador na realidade estudada. A sistematização das observações foi feita a partir da elaboração dos diários de campo. ${ }^{3}$

A outra técnica utilizada foi a Entrevista Narrativa ${ }^{4}$ (EN), que utiliza a história de vida. Segundo Jovchelovitch e Bauer (2002), as narrativas são úteis quando se investiga acontecimentos específicos ou políticas locais; projetos onde vários pontos de vista fazem parte da situação, construindo um panorama abrangente acerca de determinado fenômeno; e combinações de contextos sociais e históricos com histórias de vida. Além disso, segundo Gibbs (2009), a biografia relatada fornece voz ao ator da pesquisa, propiciando a compreensão da forma como ele constrói sua identidade.

Sobre os procedimentos, a observação participante ocorreu na área de convivência do Abrigo Provisório para pessoas em situação de rua da cidade de Fortaleza vinculadas à Secretaria Municipal de Assistência Social, como também nos diversos espaços públicos cidade onde estavam situadas as pessoas em situações de rua. Eram geralmente realizadas inserções na realidade da rua de 2 a 4 vezes por semana por um período mínimo de 3 horas. No total, o período de observação durou 8 meses consecutivas.

Para a realização de Entrevista Narrativa, foram utilizados os seguintes critérios de escolha dos participantes da pesquisa: aceitar o convite para realização da entrevista narrativa; morar pelo menos três anos na rua - por se perceber que este período é significativo para a pessoa dar sentido sobre essa situação; não possuir algum vínculo empregatício formal - por se almejar pesquisar a pessoa em situação de rua pobre que esteja privada de uma estável e mínima renda mensal; e ser adulto para se autorizar a partir da assinatura do termo de consentimento livre e esclarecido.

Com esses critérios, foi realizada uma seleção de participantes por conveniência de acordo com Marshall (1996), abrangendo 4 pessoas que aceitaram realizar a entrevista narrativa. Foram, então, fornecidos nomes fictícios de Andreza, Mario, Francisco e Aberto. Andreza é uma travesti solteira com 34 anos e um filho que reside no Maranhão. Residiu na rua nos últimos três anos e seis meses, sendo proveniente do Maranhão. Mario é solteiro sem filhos e tem 49 anos. Ele estava em situação de rua durante os últimos três anos. Alberto é solteiro e tem paraplegia. Tem 37 anos idade, estando na rua nos últimos 29 anos. Ele tem dois filhos. Francisco é o mais jovem com 23 anos de idade. Ele é solteiro e tem uma filha. Residiu na rua por volta dos últimos quatro anos.

Segundo Jovchelovitch e Bauer (2002) e Riessman (2008), a Entrevista Narrativa é analisada pela perspectiva temática. A análise temática narrativa que se constitui como um processo de redução gradual da narrativa em unidades de sentido. Essa redução gradual das narrativas dos entrevistados e dos diários de campo constituiu o processo de codificação. Segundo Gibbs (2009), essa

${ }^{3}$ Quando as informações dos diários de campo forem utilizadas, elas estarão representadas pela sigla DC, data e página correspondente no arquivo original.

${ }^{4}$ Quando as transcrições das Entrevistas Narrativas forem usadas, elas estarão composta da sigla EN junto com o nome do entrevistado e a página em que está situada a transcrição. 
codificação se refere ao trabalho de identificação de trechos do material empírico em determinadas categorias, construindo uma estrutura de sentidos da pesquisa que foram baseados nos papéis sociais da identidade social estigmatiza de pobre já apontados nos trechos anteriores. O projeto foi aprovado pelo Comitê de Ética de Pesquisa da instituição de Ensino Superior, a que estava vinculada a referida investigação.

\section{Resultados/Discussão}

Primeiramente, pode-se organizar dois grupos de papéis constituintes da identidade social estigmatizada de pobre: os fatalistas composto por características de conformado, de crente em Deus como responsável por tudo e de mártir; e os papéis de vagabundo, de causa de mazelas sociais e de culpado pela sua situação que formam os aspectos mais depreciativos dessa identidade social.

\section{Os papéis sociais do fatalismo: conformado, crente em Deus como responsável por tudo e mártir}

Identificou-se que Francisco, uma das pessoas entrevistadas, fala desse papel social de pobre como conformado: "Alguns que levam uma vida humilde, desgastada, se acomodam, não faz por onde melhorar. Está acostumado aquilo, tanto faz comer feijão com farinha, ou café com farinha" (EN FRANCISCO, p. 21). Alberto também vivencia esse papel social de conformado. Ele disse que levou um tiro de um traficante de drogas no centro da cidade. Depois fala que esse traficante ficou com sua mulher e seus filhos. Sobre isso, ele afirma: "Ai hoje tá ai, to desse jeito aqui. Ela tá lá vivendo mais ele mais meus filho e tudo, e eu to esperando aí pra mim vê o que é que vai dar" (EN ALBERTO, p. 32). Alberto, então, constitui esse papel social de conformado a partir de atitudes resignadas, não encontrando possibilidades de atuar de modo diferenciado diante de uma realidade cruel. É importante salientar, de acordo com Martín Baró (1998) e Goes (2009), que essa realidade corresponde a uma estrutura social que é opressora, tendo a reprodução do papel social de conformado como uma de suas estratégias de manutenção do status quo.

Portanto, o fatalismo é sustentado por uma realidade de opressão em que há a rigidez estrutural, a hierarquia de poder e opressão, sendo a unidade de mediação entre sujeito e mundo. Os indivíduos não percebem horizontes de mudança em suas vidas, reproduzindo constantemente o papel social de conformado. Alberto traz em sua fala esse conformismo: "Quando eu quero fazer alguma coisa que eu vejo que eu não tenho condições de fazer isso, ai eu me sinto impotente, mas aí eu dou um tempo ali. Ai levanto a cabeça e deixa pra lá" (EN ALBERTO, p. 45). Dessa maneira, a identidade é "impedida de metamorfosear-se, caminhando em uma 'invariância biográfica', em um 'círculo infindável' de repetição de si mesma, a partir do qual a identidade caminha para a "morte simbólica" (MATTOS; FERREIRA, 2005, p. 30).

Alberto se conforma como uma estratégia de sobrevivência para conseguir suportar e enfrentar sua realidade: "É questão de tempo, né? Se eu parar pra pensar, eu não posso é me desesperar, porque se eu me desesperar eu não vou conseguir os meus objetivos. Se eu tiver um pouco de paciência e de tranquilidade, eu vou, vai ter sucesso" (EN ALBERTO, p. 48). Góis (2008) afirma que os oprimidos criam estratégias de sobrevivência para enfrentar a realidade opressora. Além disso, esses indivíduos são portadores de potencialidades que podem ser enfraquecidas, mas anuladas somente com a morte biológica. Deve-se ter a mesma compreensão para identidade que é constituída de processos de mudança, mas que pode ser envolta por estratégias de cerceamento a partir de práticas de dominação constituintes da identidade social estigmatizada de pobre.

O papel social de crente em Deus como responsável por tudo seria uma dessas estratégias de enfraquecimento da capacidade ativa do indivíduo, como também, de adaptação a essa realidade de opressão (CIDADE, MOURA JR.; XIMENES, 2012). Analisou-se que Alberto vivencia esse papel social de conformado e de crente em Deus como responsável por tudo de forma concomitante: "Tenho sofrido muito, a gente sofre as coisas, né? Mas a gente vai conseguir chegar lá, se Deus quiser" (EN ALBERTO, p. 2). Já Francisco fala das consequências ruins por não ter assumido esse papel social de crente em Deus: "Eu recusei a trilhar um caminho que não existia Deus. Eu mesmo que construi aquela trilha a qual o alvo ou o foco que eu peguei não foi o verdadeiro caminho proposto [...] Poderia até viver algo bem sucedido" (EN FRANCISCO, p. 27).

Francisco e Alberto parecem seguir a lógica fatalista. Segundo Martín Baró (1998), as atitudes fatalistas estão fortemente vinculadas à fé religiosa que dificulta a compreensão crítica da realidade e que torna o ser humano passivo frente às adversidades vigentes. Dessa forma, Deus e a natureza passam a ser responsáveis pela realidade de sofrimento, sendo o destino traçado pela fé, a submissão e a docilidade atos de obediência a Deus a partir do conformismo. Observou-se que os entrevistados tem uma compreensão com pouca criticidade sobre seu contexto social opressor, pois a realidade é abordada como sofrida somente para as pessoas que não seguem Deus e que são culpadas pelo próprio sofrimento, sendo este valorizado a partir do papel social de mártir.

Identificou-se que o papel de mártir constitui a identidade de Alberto: "Eu acho que esse vai ser meu martírio, porque é, assim, quando eu to feliz demais eu já me assusto" (EN ALBERTO, p. 49). Francisco percebe a ausência da pobreza como perniciosa para si, sustentando a concepção de pobreza, como dádiva, a partir aceitação do papel social de mártir:

$\mathrm{Eu}$, futuramente, eu não quero nem ser rico, nem viver uma vida humilde, porque eu vivendo uma vida humilde um dia eu posso ignorar Deus. E eu vivendo uma vida de rico eu posso esquecer de Deus, porque Deus pode ser o dinheiro. Então, eu não quero viver nem rico, nem tão humilde, como muitos reconhece como pobres (EN FRANCISCO, p. 24-25)

Fractal, Rev. Psicol., v. 28 - n. 1, p. 76-83, 2016 
Alberto aborda a pobreza como riqueza espiritual a partir da reprodução do papel social de mártir, igualmente vinculando-o ao papel social de conformado e de crente em Deus:

[...] é pobre em coisas materiais, porque espiritual eu não me considero pobre não. Eu acho que Deus me ama, porque se ele não me amasse eu não sei o que seria de mim, né?

[...] Não, eu não sou masoquista não, mas é é uma coisa que foi eu que não foi en que procurei, mas apareceu na minha vida, eu vou ter que aprender a lidar com ela. Cada um nasce pra carregar uma cruz (EN ALBERTO, p. 49).

Francisco reproduz o papel de mártir na medida em que fala da dificuldade para alcançar alguma boa realização na vida: "Aí, então, assim, a pessoa se cuidar $e$ ver que ela tem que passar pelo estreito para chegar no largo. Ela tem que caminhar, caminhar, caminhar para depois ela descansar" (EN FRANCISCO, p. 26). Esses dois atores sociais afirmam que o sofrimento faz parte dos seres humanos, de forma que aceitam sua realidade e anulam sua indignação. Esse fatalismo, segundo Martín Baró (1998), repercute na compreensão da realidade e da história de vida da pessoa e gera um horizonte predeterminado em que não há questionamentos e enfrentamentos.

\section{Os aspectos depreciativos da identidade social de pobre a partir dos papéis sociais de vagabundo, de causa de mazelas sociais e de culpado pela sua situação}

Além dos papéis sociais relacionados ao fatalismo, a identidade social de pobre é reconhecida a partir também dos papéis vinculados à ordem capitalista e neoliberal. Segundo Cimadamore e Cattani (2007) e Raditloaneng (2009), apesar de sua origem ser anterior ao sistema capitalismo, a pobreza também é um problema mantido por essa ordem vinculada ao capital, sendo reproduzida constantemente como uma estratégia de manutenção do status quo. De acordo com Moane (2003), a estigmatização do indivíduo funciona como um mecanismo de enfraquecimento de sua capacidade de enfrentamento. Assim, em contato com um indivíduo em situação de rua em uma das praças da cidade de Fortaleza, ele fala que sofre muito por ser homem e por estar em idade produtiva, sendo reconhecido perversamente pelos outros no papel social de vagabundo. Ele diz: "Para mulher e para criança, é mais fácil. Para homem, é mais difícil, porque todo mundo manda arranjar emprego dizendo que somos vagabundos" (DC 15, 06 abr. 2011, p. 32).

Esse reconhecimento perverso do papel social de vagabundo também é impetrado pelas próprias pessoas em situação de rua que estavam no Abrigo Provisório: "Ele estava comentando que as pessoas do abrigo são preguiçosas, pois não ajudam nos afazeres domésticos de cuidado do espaço. Ele também afirmou que a maioria das pessoas do abrigo quer que as oportunidades cheguem sem elas fazerem esforço" (DC 18, 25 abr. 2011, p. 37). Além disso, as pessoas que não estão em situação de rua, geralmente, sentem medo dos indivíduos em situação de pobreza. Esses são reconhecidos como perigosos e como prováveis criminosos, a partir do reconhecimento perverso do papel social de causa de mazelas sociais. Gian- nechini et al. (2003) apontaram que essas concepções, também, são comuns nos discursos dos próprios moradores de comunidades pobres. Eles percebem as outras pessoas residentes nesse espaço, como bandidos, vinculando a pobreza à criminalidade. Um usuário do Centro de Referência Especializado em Assistência Social para população em situação de rua apresenta as consequências dessa discriminação, dizendo:

[...] "cansei de ser discriminado. O ronda vem discriminando a gente". Fala isso, porque os policiais e as pessoas em geral pensam que eles também são ladrões, porque estão morando na rua. Geralmente, são agredidos quando alguns policiais fazem buscas de drogas e de armas (DC 20, 27 abr. 2011).

E, além desse papel social ligado à causa das mazelas sociais, esses indivíduos também são vistos como culpados por sua situação, amparados por uma ótica liberal em que o mercado, de acordo com Cimadamore e Cattani (2007), é autorregulado, e o Estado tem que ter interferência mínima sobre a vida dos cidadãos. Alberto se apropriou desse papel social de culpado pela sua situação, pois ele teve uma realidade muito sofrida quando morava com os pais. Esses o faziam trabalhar muito e ainda o agrediam de forma cruel. Escolheu morar na rua para diminuir o sofrimento existente em sua vida domiciliar. Apesar disso, percebe-se como culpado pela sua situação de sofrimento:

O único culpado, assim pelo menos do meu entender, né? E do que eu passei, o único culpado sou eu mesmo, porque a minha mãe foi muito legal em me ter, me botar no mundo pra mim vê como é que ele funciona, porque se não fosse ela eu estaria no mundo ou sofrendo ou não, né? Mas, assim, pela coisa, pelo sofrimento, eu acho que o único culpado sou eu mesmo (EN ALBERTO, p. 41).

Andreza também se percebe como culpada pela sua situação: “Eu mesma sou a responsável por eu tá na rua, porque ninguém me chamou pra vir pra cá pra Fortaleza eu mesma que quis. Se eu cheguei num lugar que não tem como eu ficar, a responsável sou eu mesma de tá na rua, né?" (EN ANDREZA, p. 5). Mario também se apropria desse papel social: "Então, eu não culpo a ninguém, só exclusivamente a mim mesmo. É por isso mesmo que agora a minha obrigação é para mim consertar esse erro, pelo menos tentar amenizar, né?" (EN MARIO, p. 11). Francisco é o ator que mais enfatiza o papel social de culpado pela própria situação. Assim, ele fala: “[...] não, mas minha vida está sendo uma desgraça'ora, meu irmão, tá sendo uma desgraça, porque tu tá querendo. Porque, no momento que tu disser, 'ó, meu irmão, não vai ser mais assim, vai ser assado”. (EN FRANCISCO, p. 22 e 23). Analisou-se que esse papel social de culpado igualmente está vinculado com a ideia que os atores têm que se redimir, pois a identidade social de pobre é forjada de forma estigmatizada, depreciando o indivíduo que é reconhecido com ela. Dessa maneira, essa identidade social é símbolo do fracasso. É necessário, então, atitudes que incidam como contraponto a essa identidade, evidenciando uma tentativa de redimir atos considerados falhos.

${ }^{5}$ Ronda significa Polícia de Ronda Comunitária do Estado do Ceará. 
Esse papel social de culpado pela própria situação também é reproduzido por alguns profissionais dos equipamentos da Assistência Social pesquisados, como também por usuários desses equipamentos, reconhecendo perversamente a identidade desses indivíduos de forma opressora. Dessa maneira, esses profissionais compreendem que essas pessoas em situação de pobreza e de rua são as únicas culpadas pela sua condição (DC 7, 16 mar. 2011; DC 10, 22 mar. 2011), como também explicam que o desemprego vivido por esses indivíduos tem como a única causa uma motivação pessoal desses sujeitos (DC 16, 20 abr. 2011). Assim, há uma reprodução e um reconhecimento de papéis sociais estigmatizantes na identidade, depreciando e discriminando essas pessoas em situação de pobreza.

Como resultados desses processos de discriminação, identifica-se que pode haver a instalação de sentimentos de vergonha, culpabilizando ainda mais o indivíduo. Igualmente, outra estratégia frente a essa panorama opressor é ação violenta, funcionando como uma reação agressiva a essa sociedade cerceadora. No entanto, é importante também pontuar que as pessoas em situação de pobreza e de rua utilizam estratégias criativas para criar novas possibilidades de existência frente a esse panorama de reconhecimento depreciativo (MOURA JR.; XIMENES; SARRIERA, 2013). Apesar dessas formas de resistência, evidencia-se que é necessário constantemente questionar a realidade vigente e discriminatória, pois ela está constituída como acumulação de uma série de situação de dominação e de opressão contra as pessoas em situação de pobreza. Portanto, é premente o rompimento desse círculo vicioso de depreciamento da pessoa em situação de pobreza, construindo um novo horizonte libertador a partir de políticas de identidade emancipatórias.

\section{Considerações Finais}

A identidade social de pobre pode ser concebida como constituída de atitudes fatalistas na presença dos papéis sociais de conformado, de crente em Deus como responsável por tudo e de mártir, formando uma estrutura de manutenção e de aceitação de uma realidade desigual. De forma depreciativa, como estratégia de enfraquecimento das potencialidades e das estratégias de enfrentamento das pessoas em situação de pobreza, há o reconhecimento desses indivíduos nos papéis sociais de vagabundo, de causa de mazelas sociais e de culpado pela sua situação, podendo repercutir em sentimentos de inferioridade e de incapacidade.

Esses processos de constituição da identidade social estigmatizada de pobre tem uma origem histórica, desde a influência do catolicismo na estruturação societária da maioria dos países da América Latina até o modelo neoliberal implantado, inicialmente, pelos governos ditatoriais latino-americanos. Esses papéis sociais construídos historicamente que permeiam a realidade social, igualmente, podem constituir a identidade pessoal, aprisionando novas possibilidades de manifestação identitária que, possivelmente, seriam inovadoras e resistentes a essas formas de reconhecimento perverso.
É premente a Psicologia voltar-se a esse processo de desenvolvimento da identidade social de pobre, pois está permeado por práticas invisíveis e opressoras de produção de formas de vida conformadas, culpadas e acríticas. Entender esse processo é o primeiro passo para a elaboração de intervenções voltadas para a construção de novas possibilidades de constituição identitária e para problematização da realidade. Por fim, são igualmente necessárias maiores investigações sobre os processos de fortalecimento desses indivíduos em situação de pobreza, evidenciando como seriam essas dinâmicas de enfrentamento e de transformação dessa estrutura de reconhecimento opressora.

Além disso, os profissionais de políticas públicas voltadas para uma atuação junto ao público em situação de pobreza devem estar atentos aos mecanismos reprodutores dessas estratégias de estigmatização, pois podem ser nas formas de reconhecimento desenvolvidas por esses profissionais que essas práticas manifestam-se. Dessa maneira, o profissional deve estar constantemente refletindo sobre sua atuação, como forma de estar vigilante a reprodução dessas armadilhas ideológicas em seus espaços de trabalho que obrigatoriamente deveriam criar estratégias e ações de emancipação e de transformação social.

\section{Referências}

ANGROSINO, M. Etnografia e Observação Participante. Porto Alegre, Artmed, 2009.

ALVES-MAZZOTTI, A. J.; GEWANDSZNAJDER, F. $O$ método nas Ciências Naturais e Sociais. São Paulo: Pioneira, 1998.

BRASIL. Ministério do Desenvolvimento Social e Combate a Fome. Rua aprendendo a contar: Pesquisa Nacional sobre a população em situação de Rua. Brasília: MDS, 2009.

CIAMPA, A. C. A identidade social e suas relações com a ideologia. 1977. Dissertação (Mestrado em Psicologia Social)Pontifícia Universidade Católica de São Paulo, São Paulo, 1977.

CIAMPA, A. C. Identidade. In: LANE, T. M. S.; CODO, W. (Org.). Psicologia Social: O Homem em Movimento. São Paulo: Brasiliense, 1984, p. 58-75.

CIAMPA, A. C. A Estória do Severino e a História da Severina. São Paulo: Brasiliense, 1987.

CIAMPA, A. C. Políticas de identidade e identidade políticas. In: DUNKER, C. I. L.; PASSOS, M. C. Uma psicologia que se interroga: ensaios. São Paulo: Edicon, 2002. p. 133-144.

CIDADE, E. C.; MOURA JR, J. F.; XIMENES, V. M. Implicações psicológicas da pobreza na vida do povo latinoamericano. Psicologia Argumento, [S.1.], v. 30, n. 68, p. 87-98, 2012.

CIMADAMORE, A. D.; CATTANI, A. C. (Org.). A construção da pobreza e da desigualdade na América Latina: uma introdução. In: . Produção de pobreza e desigualdade na América Latina. Porto Alegre: Tomo/Clacso, 2007. p. 7-15.

DENZIN, N. K.; LINCOLN, Y. S. Introdução a disciplina e a prática da pesquisa qualitativa. In: _. O planejamento da pesquisa qualitativa: teorias e abordagens. Porto Alegre: Artmed, 2006. p. 15-42.

DESCHAMPS, J. C.; MOLINER, P. A identidade em Psicologia Social: dos processos identitários às representações sociais. Petrópolis: Vozes, 2009. 
GIANNECHINI, L. G. et al. Pobreza, violência e trabalho: a produção de sentidos de meninos e de meninas de uma favela. Estudos de Psicologia, [S.1.], v. 8, n. 3, p. 45-53, jan.-abr. 2003.

GIBBS, G. Análise de dados qualitativos. Porto Alegre: ArtMed, 2009.

GOES, N. A. A Psicologia Comunitária enquanto práxis libertadora. 2009. Monografia (Graduação em Psicologia)Centro de Humanidades, Universidade Federal do Ceará, Fortaleza, 2009.

GOFFMAN, E. Estigma: notas sobre a manipulação da Identidade Deteriorada (1963). 4. ed. Rio de Janeito: LTC, 2008.

GÓIS, C. W. L. Psicologia Comunitária: atividade e consciência. Fortaleza: Instituto Paulo Freire de Estudos Psicossociais, 2005.

GÓIS, C. W. L. Saúde Comunitária: pensar e fazer. São Paulo: HUCITEC, 2008.

HOWELL, R. T.; HOWELL, C. J. The Relation of Economic Status to Subjective Well-Being in Developing Countries: A Meta-Analysis. Psychological Bulletin, [S.1.], v. 134, n. 4, p. 536-560, 2008.

JOVCHELOVITCH, S.; BAUER, M. A Entrevista Narrativa. In BAUER, M. W.; GASKELL, G. Pesquisa qualitativa com texto, imagem e som: um manual prático. Petrópolis: Vozes, 2002. p. $90-113$.

IBAÑEZ, L. D. C. La Psicología de Ignácio Martín-Baró como Psicología social crítica. Una presentacíon de su obra. Revista de Psicología Geral Y Aplicada, v. 53, n. 3, p. 437-450, 2000.

LACERDA, F. C. C. A pobreza na Bahia sobre o prisma multidimensional: uma análise baseada na abordagem das necessidades básicas e na abordagem das capacitações. 2009 Dissertação (Mestrado)-Universidade Federal de Uberlândia, Uberlândia, 2009.

LANE, S. T. M. O que é Psicologia Social? São Paulo: Brasiliense, 1981.

LANE, S. T. M. A Psicologia Social e uma nova concepção de homem para a Psicologia. In: LANE, T. M. S.; CODO, W. (Org.). Psicologia Social: O Homem em Movimento. São Paulo: Brasiliense, 1984. p. 10-19.

LIMA, A. F. de. Metamorfose, anamorfose e reconhecimento perverso: a identidade na perspectiva da Psicologia Social Crítica. São Paulo: FAPESP EDUC, 2010.

MARSHALL, M. N. Sampling for qualitative research. Family Practice, [S.1.], v. 13, n. 6, p. 522-525, 1996.

MARTÍN BARÓ, I. M. Psicología de La Liberación. Madrid: Trotta, 1998

MATTOS, R. M.; FERREIRA, R. F. Quem vocês pensam que (elas) são? Representações sobre as pessoas em situação de rua. Psicologia \& Sociedade, [S.1.], v.16, n. 2, p. 47-58, mai/ago, 2004.

MATTOS, R. M.; FERREIRA, R. F. O idoso em situação de rua: sífiso revisitado. Revista Estudos de Psicologia, Campinas, v. 22, n. 1, p. 23-32, jan-mar, 2005.

MENDONCA, G. C. Os sentidos subjetivos de moradores de rua frente ao futuro. 2006. Dissertação (Mestrado)-Programa de Pós-graduação em Psicologia - Pontifícia Universidade Católica de Campinas, Campinas, 2006.

MOANE, B. Bridging the Personal and the Political: Practices for a Liberation Psychology. American Journal of Community
Psychology, [S.1.], v. 31, n. 1/2, p. 91-101, 2003.

MOURA JR., J. F.; XIMENES, V. M.; SARRIERA, J. C. Práticas de discriminação às pessoas em situação de rua: histórias de vergonha, de humilhação e de violência em Fortaleza, Brasil. Revista de Psicología, [S.1.], v. 22, n. 2, p. 18-28, 2013.

MOURA JR., J. F.; XIMENES, V. M.; SARRIERA, J. C. A construção opressora da pobreza no Brasil e suas consequências no psiquismo. Quaderns de Psicologia, [S.1.], v. 16, n. 2, p. 85-93, 2014.

MOURA JR. et al. Concepções de pobreza: um convite à discussão psicossocial. Temas em Psicologia, Ribeirão Preto, v. 22, n. 2, p. 341-352, dez. 2014.

OLIVEIRA, I. F.; AMORIM, K. M. O. Psicologia e Política Social: o trato da pobreza como "sujeito psicológico". Psicologia Argumento, [S.1.], v. 30, n. 70, p. 559-566, 2012.

PEREIRA, V. S. População de rua em Juiz de Fora: uma reflexão crítica da questão social. 2007. Dissertação (Mestrado) Universidade Federal de Juiz de Fora, Juiz de Fora, 2007.

PIVA, I. M. P. Sob o estigma da pobreza: a ação da Santa Casa da Misericórdia. In: SIQUEIRA, M. P. S. (Org.). Sociedade e Pobreza. Vitória: UFES, 2006. p. 17-29.

PRILLELTENSKY, I. The role of power in wellness, oppression, and liberation the promise of psychopolitical validity. Journal of Community Psychology, [S.1.], v. 36, n. 2, p. 116-126, 2008.

RADITLOANENG, W. N. Socialisation as a factor in poverty identity formation: a pilot casa study of the poor in selected áreas of Botswana. Convergence, [S.1.], v. 42, n. 1, p. 77-93, 2009.

RIBEIRO, D. O povo brasileiro (1995). São Paulo: Companhia das Letras, 2005.

RIESSMAN, C. K. Narrative Methods for the Human Sciences. California: Sage, 2008.

RODRÍGUEZ, P. E. La intervención clínica en contextos de pobreza y exclusión: algunas perspectivas. Revista Venezolana de Psicología Clínica Comunitária, [S.1.], v. 6, n. 1, p. 31-68, 2006

SPRANDEL, M. A. A pobreza no paraíso tropical: interpretações e discursos sobre o Brasil. Rio de Janeiro: RelumeDumnará, 2004.

SEN, A. Desenvolvimento como liberdade. São Paulo: Companhia das Letras, 2000

SIQUEIRA, M. P. S. Sociedade e pobreza. Vitória: UFES, 2006.

TAVARES, G. L. O dispositivo da criminalidade e suas estratégias. Fractal: Revista de Psicologia, Niterói, v. 23, n. 1, p. 123-136, 2011

ZAVALETA REYLES, D. The Ability to go About Without Shame: A Proposal for Internationally Comparable Indicators. Oxford Poverty \& Human Development Initiative (OPHI) Working Paper 03, May 2007. Disponível em: <http://www. ophi.org.uk/working-paper-number-03/>. Acesso em: 16 set. 2011.

Recebido em: 15 de dezembro de 2012 Aceito em: 25 de setembro de 2015 